\title{
Corrupción y la reconfiguración política en Chile: las izquierdas se autonomizan del gran capital
}

\author{
The scandals and the political reconfiguration in Chile: \\ the left are autonomous of big capital
}

Esteban Valenzuela* - Juan Castañeda** - Sebastián Gómez ${ }^{* * *}$

\begin{abstract}
Resumen: Esta investigación propone que los escándalos de corrupción dañan electoralmente con mayor fuerza a los sectores de centro izquierda, tanto alrededor del mundo, como en América Latina. No obstante, el electorado progresista, cuando tiene opciones plurales en sistemas electorales proporcionales- como el nuevo sistema electoral chileno al igual que el colombiano- castiga a los partidos con mayor vínculo a la corrupción y premia a los autónomos de las grandes empresas. De este modo, se postula que el electorado izquierdista es más estricto con sus líderes en asuntos de corrupción y logra diferenciar cuando los movimientos y partidos han naturalizado la corrupción.

La metodología del estudio es multidimensional, combinando contexto político, la intensidad de los escándalos en los medios, entrevistas a actores relevantes, observación de los niveles de confianza en los actores y análisis de los resultados electorales nacionales medidos en las elecciones de diputados de fines del 2017 comparadas con las del 2013. Luego, se realiza una categorización de los grupos políticos ganadores y perdedores colocándolos en comparación con otros casos latinoamericanos en que emergen izquierdas más autónomas y limpias versus las izquierdas más comprometidas en sus vínculos con empresas (privadas y públicas) y corrompidas en sus prácticas.
\end{abstract}

Palabras Clave: Chile, izquierdas, escándalos, reconfiguración, gran capital.

\begin{abstract}
This investigation proposes that corruption scandals damage the center-left sectors with greater force, both around the world and in Latin America. However, the progressive electorate, when it has plural options in proportional electoral systems - like the new Chilean electoral system like the Colombian one - punishes the parties with the greatest link to corruption and rewards the self-employed of the big companies. In this way, it is postulated that the leftist electorate is more strict with its leaders in matters of corruption and manages to differentiate when the movements and parties have naturalized corruption.
\end{abstract}

Keywords: Chile, lefts, scandals, reconfiguration, big capital.

Recibido: 3 febrero 2019 Aceptado: 25 abril 2019

* Dr. en Historia (Valencia) y académico de la Universidad de Concepción. evalenzuelavtgmail.com

** Doctor (c) en sociología de la Universidad Alberto Hurtado. jcastana@uc.cl

*** Abogado, Universidad de Chile. sebastiangomezsepulveda@gmail.com 


\section{Introducción: hegemonizados versus autónomos}

La principal hipótesis de esta investigación es que los escándalos sucesivos de corrupción dañan electoralmente con mayor fuerza a los sectores de centro izquierda tanto alrededor del mundo como en América Latina, pero que el electorado progresista cuando tiene opciones plurales en sistemas electorales proporcionales- como el nuevo sistema electoral chileno al igual que el colombiano- castiga a los partidos con mayor vínculo a la corrupción y premia a los autónomos de las grandes empresas. Es decir, se sugiere que el electorado izquierdista es más estricto con sus líderes en asuntos de corrupción y logra diferenciar cuando no todos los movimientos y partidos han naturalizado la corrupción como quedó demostrado en América Latina con la penetración de coimas de la brasileña constructora Odebrech como paradigma.

La metodología del estudio es multidimensional, combinando contexto político, la intensidad de los escándalos en los medios, entrevistas a actores relevantes, observación de los niveles de confianza en los actores y análisis de los resultados electorales nacionales medidos en las elecciones de diputados de fines del 2017 comparadas con las del 2013. Luego se realiza una categorización de los grupos políticos ganadores y perdedores colocándolo en comparación con otros casos latinoamericanos en que emergen izquierdas más autónomas y limpias versus las izquierdas más aburguesadas en sus vínculos con empresas (privadas y públicas) y corrompidas en sus prácticas.

El enfoque establece que existe en las grandes democracias latinoamericanas y en Chile en particular, un desapego electoral con las fuerzas política de centro izquierda e izquierda que naturalizaron tres malas prácticas estructurales: a.- vínculos orgánicos con grandes grupos económicos que minorizan las reformas y le hace administrar modelos con herencia neoliberal (Mayol 2013), b.- financiamiento irregular de campañas y partidos por liderazgos aburguesados que provienen de capas medias sin inserción social c.- formas clientelares, corruptas y autoritarias del manejo del Estado. La crisis de representación y modificación masiva de preferencias electorales se produce en coyuntura crítica en que se da amplia publicidad a casos que asume la justicia (Fiscalía y tribunales) vinculados a despilfarro de erario nacional, defraudación, colusión de empresas ante la pasividad omisiva de instituciones públicas, todas variables claves del peso de los escándalos en la percepción de las personas de la confianza institucional (Jiménez 1994; Lull y Hinerman 2000; Jacobsson y Löfmarck 2008; Neckel 2005; Thompson, 2001).

\section{La emergencia de los grandes escándalos en Chile: de Lagos a Bachelet/Piñera.}

La investigación define lo que se entiende por escándalo con consecuencias políticas y profundiza en los casos claves de la política chilena desde el 2000 hacia adelante, observando por vía de encuestas y datos electorales si hubo castigo o no a los principales actores. Se debe contextualizar que sólo a contar del 2017 se dieron dos elementos nuevos en la política chilena: a.- el fin del híper mayoritario sistema electoral binominal que favorecía a las dos grandes coaliciones tradicionales de centro derecha y centro izquierda, y b.- el surgimiento al calor de las grandes protestas estudiantiles del 2011-2013 del Frente Amplio hegemonizado por los líderes de las dos principales federaciones universitarias: Revolución Democrática con origen en la Universidad Católica y el Movimiento Autonomista más vinculada a la Universidad de Chile.

El concepto de grandes escándalos se sitúa temporalmente desde el Gobierno de Ricardo Lagos con el masivo financiamiento de altos funcionarios públicos por parte de las mismas empresas contratadas para mega concesiones en infraestructuras a cargo del Ministerio de Obras Públicas (Caso MOP-Gate), se observó en Chile un decaimiento de la Concertación de Partidos por la Democracia de centro izquierda que gobernó desde 1990 al 2010 conformada por la Democracia Cristiana (DC), Partido Socialista (PS), Partido por la Democracia (PPD) y Partido Radical (PR).

El pacto de transición de la dictadura militar a la "democracia de los consensos", implico que elementos esenciales del modelo económico extractivista se mantuvieran incólumes, la renuncia política 
al cambio de modelo de desarrollo no fue una concesión parcial de carácter táctico para acceder a la conducción del Estado, sino que representó una derrota estratégica e ideológica, se asumió por parte de las fuerzas "transformadoras" los valores sociales de las fuerzas conservadoras del sistema neoliberal.

Esta derrota estratégica por parte de la izquierda (Albamonte y Maillo 2017), provocó que desde la orfandad ideológica se pasara al derrotero político de implementar de forma autoritaria la administración del orden en forma coercitiva y/o (Trotsky 2010), así como la cooptación de los sectores subalternos como prácticas clientelares y de corrupción (Gramsci 2014) esto obliga a un control cupular de los partidos sin procesos de primarias ni elecciones transparentes, la permanencia del centralismo, siendo terreno fértil para que esta burocracia sea cooptada por grandes empresas en el financiamiento de las campañas, los partidos y las fundaciones de sus líderes (Mayol 2013; Valenzuela y Yévenes 2015).

Que la emergencia de los casos más emblemáticos de corrupción se diera durante los gobiernos que debieron enfrentar duras crisis económica (Lagos crisis asiática y Bachelet en la interminable crisis iniciada con el estallido de la crisis subprime), no es casual. La crisis de los modelos de desarrollo acelera el proceso de descomposición política de la burocracia, que al no poder recurrir al método del consenso (imposibilidad de concesiones), se apoya cada vez más en la corrupción y la violencia, como forma de dominación política.

La Concertación en el segundo Gobierno de Michelle Bachelet ya no gobierna las ciudades del norte del país ni Magallanes- optan por diferentes plataformas ciudadanas y candidaturas independientes, y los partidos cierran las puertas a su democratización interna, produciéndose significativas fracturas y desprendimientos, los cuales se suman por la izquierda a Marco Enríquez Ominami (MEO) que obtuvo el $21 \%$ en la primera vuelta de las elecciones 2009 y otros sectores se suman a Piñera que gana dichas elecciones.

Durante el Gobierno de Piñera (2010-2014) y el segundo de Michelle Bachelet (2014-2018) se destapan diversas modalidades mayores de escándalos que socavan aún más la confianza en las instituciones (Gobierno, Congreso, Poder Judicial, Partidos), lo que redunda en una progresiva decadencia de la confianza institucional de los chilenos desde 1995 en que si situaba en torno a un 65\% de credibilidad a inicios de la nueva democracia (1990-94) para situarse en promedio en torno al $20 \%$ en los rankings de confianza de hacia el 2013 (Huneeus 2014).

Junto al análisis de prensa de los casos más emblemáticos del período de reconfiguración política (2014-2017) se observarán datos de los siguientes estudios: 1) Latinobarómetro 1995 al 2015; 2) Centro de Estudios Públicos desde 2000 al 2017; 4) COES 2015, y estudios más recientes del 2018. También se citarán entrevistas realizadas a informantes claves que pidieron anonimato.

\section{El contexto latinoamericano de boom y declive de izquierdas contra la pobreza clientelares-hegemonistas sin transformaciones estructurales}

El artículo pone en contexto sudamericano el declive de liderazgos y partidos de centro izquierda al vincularse de forma orgánica al gran capital y convertirse en agente más prestigiado del mismo ante los sectores explotados y dominados de la sociedad, que terminan recreando prácticas de corrupción y clientelismos, lo que los lleva a una incapacidad material de transformar el modelo productivo extractivista que estuvo en boom por el precio de minerales, petróleo y granos. Estos gobiernos logran bajar significativamente la extrema pobreza con programas sociales de transferencias de recursos ligados a mejoras en alimentación, vivienda, salud y cobertura educacional. Sin embargo, a causa de la crisis del precio de commodities, se desnudó la ausencia de diversidad productiva, la falta de fortalecimiento estatal y social autónomo (cooperativas, sindicatos, economías comunitarias), que permita un modelo de mayor igualdad y sostenibilidad (Lander 2014).

Las izquierdas hegemonizadas (Anderson 2017) y cooptadas por el gran capital o cooptadoras de los pobres con políticas asistenciales, se dan de diverso cuño, excluyendo a Uruguay y Bolivia (previo al desconocimiento del referendo que le prohibió la reelección y después desacata), cuyo procesos por 
parte del Frente Amplio y el MAS muestran una profundización de la equidad en el caso Uruguay y una duplicación de la capacidad estatal de transformaciones compartiendo poder con municipios y departamentos en el caso de Bolivia al nacionalizar los hidrocarburos. El resto muestra aciertos en políticas a la extrema pobreza, pero grave omisión de transformaciones estructurales bien desarrolladas y abierto autoritarismo, donde es la voz de los "expertos" la que garantiza lo correcto de una política social, sin espacio de deliberación política, la economía adquiere carácter de ciencia sin elementos de valoración y menos aún sin referencia a intereses de clases, logrando de esta forma establecer un consenso, y reforzado por elementos de corrupción de los sectores dirigentes y mandos medios.

\section{a.- Partido con fuerte alianza empresarial y captura empresas estatales:}

Brasil y la alianza del Partido de los Trabajadores (PT) con Odebrecht para internacionalizar influencia y corrupción en corredores para la soya en el eje Brasil-Asia y otras materias primas (Pavel 2017). El desplome del PT por diferentes casos de corrupción fue clave para el discurso moralista de Bolsonaro de la extrema derecha que venció en las elecciones del 2018, penetrando a sectores medios del sur de Brasil tradicionalmente más izquierdistas (Pizarro 2018). En cambio, el PT defendió sus votos en el noreste donde las redes de ayuda social en zonas pobres son relevantes. De esta manera, como ocurrió con el PSOE en España, la Concertación en Chile (Durston 2012), el peronismo en Argentina, al clientelizarse los partidos y naturalizar la corrupción, pierden sus votos en las grandes ciudades y se mantienen más fieles segmentos pobres de voto subsidiado por los programas sociales (Corzo 2002).

El kichnerismo naturalizó en Argentina el financiamiento ilegal estable proveniente de empresas privadas y al igual que brasileños con Petrobras, se sucedieron escándalos en el manejo de las empresas públicas para el enriquecimiento privado de dirigentes y financiamiento de las redes leales a la corriente hegemónica, en muchos casos aliados a redes Venezolanas, como documentó la izquierdista Margarita Stolbizer (2016)

\section{b.- La Alianza del Pacífico: Chile, México, Colombia y Perú en las redes neoliberales.}

La política del eje "liberal" del Continente ha estado dominada por corrientes de derecha y de centro izquierdas vinculadas a las grandes empresas que financian sus fundaciones en Chile (de la Democracia Cristiana al laguismo en el Partido Socialista y el Partido por la Democracia), México (tanto el PAN como el histórico PRI y su escisión del PRD que se alió a la derecha en las elecciones del 2018), Colombia (el Partido Liberal histórico y sus diversas corrientes) y Perú (los entornos y los presidentes Toledo, Alán García y Humala, todos acusados de corrupción, más allá de sus retórica sociales). Como se demostrará en el caso de Chile, por la captura de la centro-izquierda por los grandes grupos económicos. Caso paradigmático de esto es el financiamiento por parte de la empresa SOQUIMICH, la que fue privatizada bajo la dictadura militar de Augusto Pinochet y traspasada a su yerno Ponce Lerou (Mayol 2013, Matamala 2015), con avances en bajar extrema pobreza, pero mantenimiento del modelo primario exportador de baja tributación y privatización de servicios sociales (previsión, salud, agua, electricidad), lo que redunda en malestar y desigualdad a pesar de sus mejoras macro en índices de desarrollo con desigualdades territoriales (PNUD 2019).

\section{c.- E1 Eje Bolivariano: corrupción y autoritarismo.}

El llamado Eje boliviariano donde Venezuela vive la mayor crisis de su modelo rentista petrolero ante la incapacidad y corrupción del supuestos socialismo del Siglo XXI que se convirtió en una cúpula militar de repartición de renta sin transformaciones (Lander 2014), en alianza con gobiernos crecientemente autoritarios como Nicaragua de Daniel Ortega que no aceptan oposición real que genera la esencial controversia (Arendt 1997). Una suerte de izquierda presicrática- presidencialista centralista- que 
corrompen los valores democráticos del socialismo consejista federal, en el viejo dilema de asaltar el Estado para crear nuevas burocracias políticas o burguesías fiscales o hacer revoluciones y/o reformas estructurales con control social, participación y mayor igualdad (Valenzuela 2017). La imposibilidad de aceptar oposiciones o de auto actividad de las clases subalternas, que ponen en riesgo los privilegios y prebendas obtenido al amparo de la administración de los recursos públicos o incluso la misma necesidad de la burocracia (Mandel 1994), compran y reprimen actores colectivos independientes del bloque dominante de poder (Gandhi y Przeworski, 2005).

La centro-izquierda al verse privada de toda posibilidad de transformación minorizada por los tecnócratas de la dictadura del consenso rompiendo la fuerza de lo diverso en la propia sociedad americana con la imposición de la figura del caudillo militar o político populista salvador, con los matices entre ellos (Laclau 2005), en vez de fortalecimiento de sindicatos y movimientos sociales territoriales (Salazar 2013). La burocracia separa el Estado de la sociedad civil (Artous 2016), y reconoce en la autoactividad de las masas el peligro a su existencia (Mandel 1994), la cuales requieren de la mayor participación en asuntos de gobiernos, para evitar la usurpación de derechos y conquistas.

García Linera (2015) relata como la izquierda iluminista creció al fundirse con los movimientos campesinos e indigenistas en el MAS, al igual que zapatistas y las nuevas izquierdas que no quieren el personalismo extremo con estructuras paralelas y corruptas de financiamiento de la "organización" y enriquecimiento ilícito vía brokers. El propio Evo Morales se enfrenta a las propias tendencias progresistas de aliados de él que lo abandonan por la no aceptación de otros liderazgos basado en una política de izquierda comunitarista

El en caso de Chile, Jonh Durston hizo una cartografía de las redes cooptativas en las regiones de la Araucanía, Bío-Bío y Coquimbo: "El clientelismo está profundamente incrustado (embedded) en las instituciones y prácticas políticas de las regiones estudiadas, compenetrando gran parte del aparato público con el cual interactúan los sectores populares" (Durston, 2012: 369). Dichas maquinarias se fueron alimentando de la captura de instituciones públicas y cada vez mayor dependencia al financiamiento ilícito privado agravado ante la ausencia de financiamiento legal de partidos y primarias hasta la coyuntura del destape de los grandes escándalos 2014-16.

\section{El caso Caval: daño a la imagen de Bachelet y su Gobierno}

Aunque los casos más graves de abusos se vinculan a grandes empresas vinculadas a la Unión Demócrata Independiente (UDI), el caso CAVAL (febrero del 2015) afectó a Bachelet a través de la relación familiar con Natalia Compagnon, aunque también dos tercios de los actores pertenecen a dicho partido de derecha. Se trata de un negocio vinculado a la compra de terrenos en la localidad de Machalí cercana a la Rancagua. La investigación detalló los negocios inmobiliarios de la nuera Natalia Compagnon -esposa del hijo de la mandataria, Sebastián Dávalos- logró conseguir un cuantioso financiamiento del principal banco privado del país (el Banco de Chile de la familia Luksic, principal grupo económico del país) a pocos días de ganar la presidencia en diciembre del 2013. Caval es la empresa de exportaciones y gestión de la nuera Compagnon con un empresario vinculado a la UDI, llamado Mauricio Valero. El préstamo de diez millones de dólares les permite comprar un terreno de 44 hectáreas en la Carretera del Cobre con gestión de Herman Chadwick- sobrino del Ministro del Interior de Piñera, Andrés Chadwick-, con el objeto de revenderlo quintuplicado al transformarlo de agrícola a urbano en gestiones en el Municipio de Machalí (1996) gobernando también por alcalde y funcionarios de la UDI. Aliados a un empresario mexicano exponían la llegada de una mega ciudad con oficinas y edificios de departamentos en una zona que el plan intercomunal del Gran Rancagua había dejado explícitamente como zona agrícola de baja densidad habitacional para evitar el colapso de la carretera en que circulan 15 mil trabajadores en buses a laborar en tres turnos a la principal mina de cobre subterránea del mundo: El Teniente de la empresa pública CODELCO. Sus efectos se relacionaron por un lado en la obtención de un cuantioso préstamo sin respaldo patrimonial y en presiones para la modificación del uso del suelo en esta comuna, en 
definitiva, esta "gestión política" es el único "valor" que aporto la empresa CAVAL a la operación financiera. Las evaluaciones ciudadanas sobre este caso fueron importantes. A la alta cobertura mediática de un hecho relacionada con la Presidencia de la República, los medios comenzaron a investigar intensamente los posibles delitos vinculados a estas transacciones comerciales (Ciper, 2015).

Aunque el evidente caso de tráfico de influencia culminó con condenas menores para Natalia Compagnon- la que fue acusada de otros casos de lobby en cambios de uso de suelo, construcción de hospitales y eventuales acceso de derechos de agua-, la Fiscalía de Rancagua mantuvo todo el período el caso vivo hasta las elecciones del 2017, y la prensa dominada por grupos empresariales "logró que la derecha acosada por casos muchos más graves empatara en la percepción de la opinión pública con la centro izquierda y con el gobierno en la percepción de corrupción, paralizando a la Presidenta que se afectó en lo personal y se distanció de Natalia Compagnon y sus nietos al pedir que su hijo saliera del cargo de coordinador de las fundaciones presidenciales (GA, asesor encuestas gobierno). Bachelet perdió en todas las encuestas atributos de probidad y por este factor y otros vinculados a una gestión gubernamental inapropiada que "no fue pragmática en reformas para mostrar resultados y no reaccionó frente a otros escándalos- como pensiones millonarias de uniformados y funcionarios públicos ligados al oficialismo socialista, sucumbió en su popularidad vinculando a toda la centro izquierda a la burguesía fiscal (entrevista a Edison Ortiz, doctor en historia y columnista de El Mostrador ${ }^{1 "}$.

\section{Penta, Papeleras y Pesqueras: los escándalos de la UDI}

En agosto del año 2014 el Servicio de Impuestos Internos de Chile (SII), recibe una denuncia sobre adulteración de declaraciones de impuestos y el uso de mecanismos tributarios que tenían como objetivo el financiamiento irregular de la política. El procedimiento consistía en solicitar a una serie de contribuyentes, documentos contables denominados boletas de honorarios, sin que los trabajos profesionales se hubieran realizado. Con estas prácticas se eludía el pago de impuestos y sobre todo se lograba financiar al partido principal de la derecha chilena (la Unión Demócrata Independiente, UDI), a una serie de políticos de la misma posición ideológica y otros ligados a la alianza de gobierno de la primera administración Bachelet.

Los principales actores de un caso denominado Penta son los empresarios Carlos Eugenio Lavín y Carlos Alberto Délano, ambos ligados a la UDI- financistas y miembros de su Comisión Política en diversos momentos-, acusados por Hugo Bravo, su exgerente general del holding, de gestores de operaciones tributarias fraudulentas (Jorge Valdivia como enlace entre los contribuyentes o Iván Álvarez un funcionario del SII) que incluían hasta evasión de patentes municipales pero sobre todo masivos recursos a la UDI (Monkeberg 2015, 2017). El grupo Penta nació junto a las privatizaciones de la dictadura (Monkeberg 2001) teniendo poder en los sistemas de pensiones y salud, seguros y otros múltiples.

El análisis del caso Penta permite identificar la importancia de los medios de comunicación en la visibilización de escándalos políticos que pueden influir sobre la confianza en la política, en los políticos y en las preferencias ciudadanas por la búsqueda de calidad democrática de la opinión pública (Montero, Zmerli y Newton, 2008). Aunque la derecha buscó sus medios evitar el vínculo a las empresas (Matamala2015), fue inevitable la sanción ciudadana ante la magnitud del escándalo. Al contrastar el tratamiento mediático diferenciado, en términos de construcción del fenómeno de escándalo político tomando en consideración las posiciones ideológicas de los medios de comunicación, en este caso de prensa de carácter electrónica. El diario electrónico El Mostrador (progresista) durante el 2015 identifica a los actores involucrados en el uso de boletas ideológicamente falsas y la defraudación al fisco que con ello conllevó. En el caso de Emol (portal de El Mercurio, conservador), la defraudación no es clara y queda en el ámbito de la interpretación (Castañeda 2018: 103).

${ }^{1}$ Entrevista el 18 de abril 2018. 
A lo anterior se sumó el fin del líder de la UDI- ex presidente del partido y candidato presidencialPablo Longueira y los ex senadores Jovino Novoa y Jaime Orpis- acusados de múltiples delitos tributarios, pero especialmente el vínculo con pesqueras (caso Corpesca) en que Longueira siendo ministro del primer gobierno de Piñera y Orpis senador, reciben instrucciones explícitas de pesqueras y mineras para modificar leyes a favor de los grupos económicos.

El ánimo social con la UDI cambió definitivamente con un tercer caso vinculado a connotados miembros de la misma y gestores del Centro de Estudios Públicos (CEP), la familia Matte, dueña de la emblemática CPM (principal Papelera, líder de la oposición a Allende en 1970-93), la cual es descubierta que por años se coludió con otras empresas para dominar el precio del papel tissue de uso doméstico y evitar la entrada al mercado de nuevos competidores. Los datos electorales de la UDI la hicieron perder un tercio de su votación en diputados, del 23\% el 2009 a un 15,7\% el 2017, lo que se agudizó con su baja a casi la mitad en el senado de un 21,3\% al 12,7\%. (SEREVEL 2018).

\section{La empresa del yerno de Pinochet que afectó a la izquierda}

El caso Soquimich (SQM) estallaq en enero de 2015 al informar Canal 13 sobre las investigaciones judiciales que vinculaban el caso Penta y la empresa de minería no metálica Soquimich (SQM). Esta arista pasó a ser identificada por los medios de comunicación como la arista SQM, por las siglas de la ex minera estatal. En los meses de agosto a septiembre de 2015, el periódico digital, El Mostrador, realizó un análisis de los actores políticos involucrados para establecer conexiones entre el caso Penta y la financiación irregular de la política. En un reportaje publicado el 21 de agosto de 2015 y titulado "Santiago Valdés, el Peñailillo de Piñera (administrador electoral de la campaña presidencial del ex presidente Sebastián Piñera)", el medio periodístico estableció un nexo no solo entre las coaliciones políticas (la Nueva Mayoría y Chile Vamos), sino también entre Penta y SQM. Había nacido el caso que provocaría la caída de la hegemonía exclusiva de las dos coaliciones tradicionales en el Congreso, pero que afectaría fuertemente a la izquierda.

El caso SQM mostró el fuerte financiamiento de esta empresa de origen pinochetista a la centro izquierda, "probablemente porque su origen oscuro al quedar el yerno de Pinochet, Julio Ponce Lerou, como dueño por unos pocos millones en plena dictadura, llevó a Ponce a buscar aliados en la Concertación y la izquierda para que nadie cuestionara su propiedad, financiando de manera impúdica a sus supuestos enemigos políticos (Maurico Daza, principal querellante contra SQM de Corporación Ciudadano Inteligente)"2.

La Concertación fue la más afectada por SQM al conocerse masivos pagos a candidatos de la Democracia Cristiana como el senador Jorge Pizarro y al PPD, donde salió dañada la figura de Carolina Tohá, alcaldesa de Santiago, quien perdió su reelección (fines del 2016) en medio del destape de triangulaciones tanto al partido cuando ella era presidenta del mismo como a sus campañas. En el caso de ella, el electorado de izquierda les castiga duramente al igual que la Marco Enríquez Ominami (MEO $\left.{ }^{3}\right)$ en la candidatura presidencial del 2017, porque ambos "son hijos de figuras relevantes, el ministro José Tohá de Allende y el líder del Movimiento de Izquierda Revolucionaria, Miguel Enríquez, ambos asesinados por Pinochet, haciéndose inconcebible que reciban dinero de su ex yerno, como se comprobó en los focus groups (GA, asesor encuestas Gobierno Bachelet)".

\footnotetext{
2 Entrevista el 20/8/2018.

3 MEO era la estrella de la nueva izquierda en el año 2009 cuando salió tercero con el $21 \%$ de los votos, bajando a $11 \%$ con la popular Bachelet en competencia el 2013, pero hundiéndose al 5\% el 2017 en medio de las formalizaciones legales en su contra por recibir dinero con asesorías falsas de SQM, otras empresas y declarar como gasto los vuelos en el avión privado que le prestó la constructora Odebrecht brasileña, primordial en los escándalos en Sudamérica.
} 


\section{Escándalos, transformaciones políticas y perdedores electorales}

Los escándalos analizados al ser graves, tener la legitimidad de la acción judicial, malestar ciudadano expreso y fuerte presencia mediática, se tradujeron en dos factores claves: algunas transformaciones políticas y claros perdedores en la escena política de las elecciones 2016 (municipales) y 2017 (presidencial y parlamentaria), lo que coadyudó a una reconfiguración del sistema político.

La debilidad de los partidos de derecha, especialmente la UDI, permitió modificar el sistema electoral binominal (dos parlamentarios por distritos) que había dominado la escena política tras su implantación en la Constitución de Pinochet de 1980 y puesta en funciones en 1989 (Huneeus 2014). La propia baja en las encuestas de la UDI "nos hizo reflexionar equivocadamente de que nos convenía sobrevivir como primera fuerza en un proporcional corregido ya que seguiríamos en torno al $18 \%$ en diputados y $15 \%$ en senadores. Bajamos más y en el Senado quedamos minimizados (JR, experto electoral UDI). No obstante, la oposición de la mayoría de sus parlamentarios, hubo votos UDI y Renovación Nacional para modificar el binominal.

Una segunda reforma relevante que vetaba también la UDI, fueron las reformas electorales emanadas de la llamada Comisión Engel en referencia al ingeniero de la Universidad de Chile que la encabezó, la que concluyó con un sistema de financiamiento a los partidos (no sólo campañas), escrutinio público de los recursos de los mismos y obligatoriedad de primarias (Engel 2015). La UDI era el partido más resistente a estos procesos. De hecho, "Renovación Nacional al ser el partido más abierto a realizar primarias desde el 2009, cuestión que practicó a diferencia de la UDI, generamos una lógica inclusiva y reclutadora de liderazgos territoriales que junto a la caída de la UDI por los escándalos, nos convirtió en el primer partido del país (Aldo Casini, director del Instituto Libertad)"4.

De este modo, al igual que el anterior caso MOP-Gate en el gobierno de Lagos, la apertura de la UDI a levantar el veto a transformaciones, permitió los votos para hacer cambios relevantes. El llamado acuerdo Lagos-Piñera permitió crear la Alta Dirección Pública en el año 2003 y elevar sustancialmente los salarios de los funcionarios públicos en respuesta al escándalo de sobre sueldos desde las empresas privadas y públicas. La reforma tributaria del 2014 permitió mayores normas ante elusión y evasión de impuestos, e impuso severas penalidades y destitución en algunos casos a políticos con financiamiento ilegal.

El otro resultado de las elecciones son los grandes perdedores: a.- la Nueva Mayoría que pierde el poder y baja del $40 \%$ que obtuvieron sus candidatos en promedio en la primera vuelta desde el regreso de la democracia (incluyendo al PC más votos Concertación) a sólo un 22.7\% con Guillier el 2017, y del $55 \%$ del Parlamento a un 35\% del mismo; b.- la UDI que pierde en promedio el $40 \%$ de su representación parlamentaria como porcentaje del Congreso.c.- MEO y su partido PRO que obtienen un $5.7 \%$ en la presidencial y menos del 3\% en la parlamentaria, debiendo fusionarse con otro partidos para subsistir.

\section{Gana Piñera, pero emerge la izquierda autónoma del Capital}

Piñera ganó holgadamente la segunda vuelta presidencial en diciembre del 2017 con un 57\% por sobre el $43 \%$ del candidato de la Nueva Mayoría, Alejandro Guillier, no obstante, su 23\%, sumado al 21\% de Beatriz Sánchez del Frente Amplio y lo obtenido por MEO de los progresistas (5\%) y otros dos candidatos izquierdistas (2) sumaban una mayoría, dejando el voto de la Democracia Cristiana en una indefinición (5\%). Sin embargo, la centro-izquierda venció en el senado con mayor continuidad de fuerzas, pero tuvo una fuerte reconfiguración en la Cámara de Diputados. De esta manera, una elección, debido según diversos analistas por cinco razones:

${ }^{4}$ Entrevista realizada el 20/8/2918. 
a.- Las altas expectativas de que él reimpulsaría la economía que había bajado del $5 \%$ de crecimiento en el período Piñera 2010-13 a un 2\% con Bachelet 2014-2017. Aunque la baja en los precios del cobre y otras materias primas no generó una recesión ni un alza en el desempleo, el cambio de humor económico fue relevante y la idea positiva en torno a Piñera: "Nuestras encuestas mostraban un $70 \%$ de pesimismo si ganaba Guillier en materia económica, en cambio, un mismo $70 \%$ reconocía que con Piñera mejoraría la inversión y el crecimiento, incluyendo electorado de centro izquierda (JR, experto electoral UDI)".

b.- El desplome en todos los atributos de la Nueva Mayoría observada como "una coalición de burócratas y políticos corruptos que ganan altos sueldos y que no hacen nada por mejorar las pensiones y la salud, ni enfrentar a las empresas que los financian (GA, asesor encuestas Gobierno de Bachelet)". El propio Alejandro Guillier reconoce que "el desgaste de la coalición y el apoyo de los partidos pésimamente evaluados por la ciudadanía, además de la campaña de la posverdad de la derecha de que yo provocaría un Chilezuela, fueron los factores claves de la derrota5". Así perdió sus atributos de independiente y ciudadano honrado el afamado periodista televisivo y senador del norte con discurso regionalista que partió primero en las encuestas y fue perdiendo progresivamente.

c.- Piñera logra quedar inmune a los numerosas investigaciones que le acecharon y tocaron directamente- Longueira fue su ministro, su subsecretario de minería Wagner fue condenado por cohecho, su asesor financiero estaba vinculado a Penta, entre otros-, en base a un acuerdo transversal invisible del llamado partido del orden (Ortiz 2018) de no tocar a los presidentes, ya que había razones para llevar a la Fiscalía tanto a Bachelet por el financiamiento de su campaña como a Piñera por los mismos casos de empresas financistas en forma ilegal. El Centro de Investigaciones Periodísticas, CIPER, desclasificó numerosas aristas del financiamiento ilegal a Piñera en sus campañas del 2009 y 2017 que la justicia no indagó. ${ }^{6}$

d.- Piñera logra convocar a las dos nuevas derechas con electorados activos que permiten morigerar el impacto negativo de la UDI en la opinión pública. En la colaición Chile Vamos ocupa una fuerte presencia Evopoli (Evolución Política) de Felipe Kast que con un discurso centrista captó electorado descontento de la Concertación y de su alianza con el Partido Comunista. Evopoli obtuvo el $4,5 \%$ de los votos nacionales, con seis diputados y dos senadores.

En el otro extremo de la derecha, el ultra conservador José Antonio Kast- primo del centrista de Evopoli-, con su $8 \%$ en la primera vuelta electoral fue clave en su llamado activo a vencer a la izquierda para que el electorado de derecha se movilizara activamente por Piñera que había obtenido sólo un 36,6\% en la primera vuelta. De este modo hubo una suerte de verdadera "lucha de clases electoral", ya que con una participación electoral menor al 50\%, las comunas de las zonas pudientes del gran Santiago rompieron todos los records al votar en torno al $80 \%$ de los votos, e incluso más como Vitacura $(87,99 \%)$, Lo Barnechea $(86,40 \%)$ y Las Condes $(81,75 \%)$.

e.- En el lado opuesto, las comunas populares votaron en menor medida incluyendo la zona sur del gran Santiago donde Guillier ganó, pero con una participación electoral de solo el 30\% promedio.

En estas zonas del gran Santiago y Gran Valparaíso, y en las tres regiones donde logró empatar y ganar Guillier (Arica, la ciudad de Valparaíso Magallanes y Aysén), se dio una combinación de mayor inversión pública (plan de zonas extremas en el caso regional e inversión social y en salud en zonas urbanas populares) y una fuerte votación del Frente Amplio que las lidera con alcaldes y parlamentarios.

El Frente Amplio (FA) es el gran ganador de las elecciones con Beatriz Sánchez que casi pasa a la segunda vuelta con su 20,3\% de los votos y que irrumpió con 20 parlamentarios como tercera fuerza política del país. El FA nace con hegemonía de los movimientos vinculados a los líderes de las exitosas protestas estudiantiles en favor de educación de calidad, pública y gratuita del 2007 al 2012 (Revolución

\footnotetext{
${ }^{5}$ Entrevista en Radio Rancagua 3/8/2018.

6 Ver entre otros: https://ciperchile.cl/2017/09/26/los-pagos-de-sqm-a-proveedores-de-la-campana-de-sebastian-pinera-en2009/ https://ciperchile.cl/2018/01/03/instagis-el-gran-hermano-de-las-campanas-politicas-financiado-por-corfo/ visitados el 29/8/2018.
} 
Democrática de Giorgio Jackson de la U. Católica y Movimiento Autonomista de Gabriel Boric de la U. de Chile, ambos primeras mayorías porcentuales como diputados), aglutinando también a otros grupos izquierdistas y movimientos ciudadanos hastiados de la clase política de altos salarios (elementos semejantes al auge del Podemos en España, Movimiento Cuatro Estrellas en Italia, Siryza en Grecia). Sus lógicas son menos democráticas que el Frente Amplio uruguayo que privilegia primarias y alta participación, debido a la reproducción de las visiones vanguardistas e iluministas de estos dos movimientos de origen estudiantil (Mayol 2017).

Los líderes del Frente Amplio llamaron a votar por Guillier pero la respuesta fue mayor en sus ciudades que en los sectores populares que "abandonaron con su abstención a la centro izquierda acusada de burguesía fiscal acomodada y sin consecuencia. No ganó Piñera, perdimos nosotros (GA analista electoral Gobierno Bachelet)".

El otro grupo ganador que irrumpió fue la Federación Regionalista Verde Social, FREVS, formada por disidentes DC, PPD y ecologistas federalistas junto a un segmento del movimiento mapuche en favor de autonomía territorial. Obtuvo 4 diputados de los 5 distritos en que compitió y sumo al independiente René Saffirio para constituirse en el comité clave que asegura mayoría estable a la centroizquierda en la Cámara de Diputados.

\section{Conclusión: Piñera moderado por la cohabitación y la irrupción de la izquierda autónoma del Gran Capital}

Sebastián Piñera asumió el poder en marzo con un programa restauracionista moderado con énfasis conservadores que ha debido morigerar incluso más producto de la mayoría centro izquierdista en la Cámara (83 versus 72 de la derecha) y en el Senado (24 versus 19 de la derecha), ambos brazos del legislativos presididos por socialistas que logran mantener el diálogo con Frente Amplio y Regionalistas y la ex Nueva Mayoría que desaparición como coalición al declararse la Democracia Cristiana partidaria de rehacer la antigua Concertación más al centro.

El programa de Piñera no fue ambicioso en el aspecto legislativo ni prometió profundizar reformas en la línea trazada por Bachelet, que puso en marcha la gratuidad educacional y envió un proyecto desechado de cambio previsional mixto manteniendo la cotización individual combinada con un fondo de reparto. Piñera desechó ese proyecto y anuncia otra iniciativa. Su énfasis ha estado en regular la fuerte corriente migratoria hacia Chile de haitianos, dominicanos, venezolanos y colombianos (reinstaló la exigencia de visas e informes policiales, frenando la ola migratoria); activar la economía que desde el último trimestre de Bachelet viene subiendo al $5 \%$; presentar una reforma tributaria simplificadora que premiaría reinversión de las empresas. Esta iniciativa ha generado fuerte resistencia por favorecer a los más ricos y apertura de los regionalistas en la medida que incluya rentas para las regiones que por primera vez elegirán gobernadores en forma democrática a fines del 2020.

Otro ámbito de preocupación ha sido el policial, descabezando a Carabineros, la prestigiosa policía que había sufrido un grave escándalo de corrupción en las altas esferas ligadas tanto a sistemas paralelos de pagos salariales e invención de causas falsas contra los mapuches por parte de sus unidades de inteligencia. En ese mismo ámbito, en el énfasis empresarial de Piñera, nombró al líder privado y ex canciller, Alfredo Moreno, como Ministro de Asuntos Sociales con tarea especial de dialogar y aumentar la inversión en la empobrecida Araucanía donde los sabotajes de los mapuches a las forestales siguen ocurriendo en un conflicto que no tiene salida sin negociación directa.

La opinión pública chilena es impaciente y crítica (PNUD 2017) y las encuestas mandan la política (Castells 2009), ya que sólo el 40\% apoya la reforma tributaria y establece la baja de Piñera del 60\% de aprobación a un a 45\% (CADEM 2018), lo que lleva a la Presidencia a propiciar acuerdos amplios y ser muy activos en lo mediático.

La criminalidad no disminuye (baja en muertes violentas, creciendo en robos y asaltos). Se proyecta de este modo que, sin mayores recursos y reformas rápidas, crecerá el malestar y un nuevo ciclo 
de protestas que lleve al poder al Frente Amplio aliado con regionalistas y la ex Nueva Mayoría. Beatriz Sánchez y los jóvenes Jackson y Boric son los políticos mejor evaluados por los chilenos (CADEM 2018) y la alternancia parece imponerse como parte del buen gobierno (Rosavallón 2015).

Chile completará treinta años de nueva democracia estable en la que presidentes moderados han gobernado siendo compelidos a realizar transformaciones y mejoras al modelo que Manuel Antonio Garretón (2012) sintetizó como "neoliberalismo corregido, progresismo limitado" connotando cambios incrementales hasta el ciclo de mayores transformaciones que empujó el movimiento estudiantil con la profunda reforma educacional del segundo gobierno de Bachelet. Los cambios han provenido de la calle y los escándalos cuando la justicia los ha tomado colocando a la burocracia política en la obligatoriedad de legislar. Es lo que ocurrió en la coyuntura de cansancio ciudadano ante los diversos casos de corrupción. Dicho malestar sumado a la trama de nuevas agendas y actores, produjo un clivaje que reconfigura el cuadro político, aunque repita su mandato un presidente de la centro-derecha como Piñera. De este modo, los escándalos tuvieron efectos con un saldo de perdedores, estables y ganadores de la reconfiguración política que implicó la última elección "nacional" entendiéndola como parlamentarias y presidencial del año 2017.

Partidos Perdedores, Estables y Ganadores con los escándalos en Chile 2013 y 2017: \% de votos en elecciones de diputados

\begin{tabular}{|l|l|l|l|}
\hline Partido/Datos & $\begin{array}{l}\text { Situación ante Principales } \\
\text { Escándalos asociados }\end{array}$ & $\mathbf{2 0 1 3}$ & $\mathbf{2 0 1 7}$ \\
\hline UDI & $\begin{array}{l}\text { Líderes históricos condenados: Longueira, Novoa } \\
\text { y Orpis. Reos Dueños del grupo PENTA, } \\
\text { financistas junto a pesqueras }\end{array}$ & 19 & 15,9 \\
\hline $\begin{array}{l}\text { PPD } \\
\text { Perdedor }\end{array}$ & $\begin{array}{l}\text { Figuras del Bacheletismo cuestionadas (Peñailillo, } \\
\text { Ministro del Interior), Financiamiento SQM }\end{array}$ & 11,3 & 6,1 \\
\hline $\begin{array}{l}\text { DC } \\
\text { Perdedor }\end{array}$ & $\begin{array}{l}\text { Senadores y diputados en financiamiento de SQM, } \\
\text { Pesqueras }\end{array}$ & 15,5 & 10,3 \\
\hline $\begin{array}{l}\text { PRO (lista MEO) } \\
\text { Perdedor }\end{array}$ & Financiamiento SQM Obredecht y facturas falsas & 5,3 & 3,3 \\
\hline $\begin{array}{l}\text { PS } \\
\text { Estable }\end{array}$ & Sin mayor vinculación & 11,1 & 9,8 \\
\hline $\begin{array}{l}\text { PC } \\
\text { Estable }\end{array}$ & Sin mayor vinculación & 4,1 & 4,6 \\
\hline $\begin{array}{l}\text { PR } \\
\text { Estable }\end{array}$ & Sin mayor vinculación & 3,6 & 3,6 \\
\hline $\begin{array}{l}\text { R. Nacional } \\
\text { Ganador }\end{array}$ & Sin mayor vinculación & 14,9 & 17,8 \\
\hline $\begin{array}{l}\text { Evopolis } \\
\text { Ganador }\end{array}$ & Críticos & 1,3 & 4,3 \\
\hline $\begin{array}{l}\text { F. Amplio } \\
\text { Ganador }\end{array}$ & Críticos & 5,7 & 16,5 \\
\hline $\begin{array}{l}\text { Regionalistas } \\
\text { Ganador }\end{array}$ & Críticos & 1 & 2,5 \\
\hline
\end{tabular}

Fuente: En base a resultados del SERVEL 2013 y $2017 .{ }^{7}$

\footnotetext{
7 No se contó cantidad de escaños ya que subió el 35 el número de los mismos. En el caso del FA se sumó los grupos que lo componen y los independientes el 2013 (PH y diputados Mirosevic, Boric y Jackson). En el caso de los Regionalistas y Evopoli se tomó la votación de sus diputados que eran independientes el 2013.
} 
El anterior cuadro permite ponderar la relación directa entre posturas involucradas en los escándalos, neutra y el favorecimiento a sectores críticos (Frente Amplio, Evopolis y regionalistas). Renovación Nacional no tuvo mayor involucramiento, no obstante consultora asociada que hacía informes a las empresas, pero lejos del masivo financiamiento legal e ilegal de los grandes grupos económicos a la UDI, Democracia Cristiana, PPD y se SQM a MEO.

Del mismo modo, se puede apreciar, que la alianza Chile Vamos (RN, UDI, Evopolis) que apoyó a Piñera suma sólo el $40 \%$ del electorado, lo que explica tanto los atributos personales asociados a su moderación, credencial antidictadura (fue parte de la campaña del No en el plebiscito del año 1988 a Pinochet) y capacidad de emprendimiento económico, no obstante, el ruido por sus inversiones y acusaciones a cercanos y colaboradores que estuvo presente en la coyuntura 2013-2017. El desplome en la confianza ciudadana con Bachelet y la gestión de su coalición, en especial con la Democracia Cristiana y PPD, favoreció la baja de la centro- izquierda tradicional y la emergencia de frente amplistas y regionalistas. Debido a la pluralidad de fuerzas representadas en el Congreso, el gobierno de Piñera se le dificulta formar una mayoría estable para la aprobación de su agenda restauracionista, lo que genera la consiguiente imposibilidad de gobernar mediante grandes consensos como en la década de 1990.

Frente a esta debilidad el gobierno de Piñera ha comenzado a "legislar" a través del Tribunal Constitucional, develando el carácter profundamente autoritario y antidemocrático de la institucionalidad que se forjo a la sombra de la dictadura militar que rigió Chile 1973-1989, el Tribunal Constitucional ya ha limitado los avances en materia de Tutela Laboral respecto de los trabajadores del Estado ${ }^{8}$, derecho al aborto al permitir que las instituciones que niegan a practicar este procedimiento aún sean financiadas por recursos públicos ${ }^{9} \mathrm{y}$ la igualdad ante la ley al rebajar multas a empresarios ${ }^{10}$.

Así, nos encontramos que, a pesar de la mayor diversidad parlamentaria, el modelo de desarrollo extractivo es incapaz de entregar concesiones que permitan la reconstrucción de un nuevo consenso nacional, por lo que los partidarios de este se refugian en instituciones aún menos democráticas, para evitar cualquier tipo de modificación. La pregunta que surge ¿será capaz la izquierda no ligada al gran capital, de formular una estrategia para desarmar el cerco institucional que garantiza la continuidad del modelo económico de carácter primario?, y que cada vez que parece romperse se contrae hacia un sistema aún menos democrático, ¿̇ terminara adaptándose a lo ya existente?

\section{Referencias Bibliográficas}

Emilio Albamonte y Matías Maiello, Estrategia socialista y arte militar, Buenos Aires, Ediciones IPS, 2017. Perry Anderson, The H-Word The Peripeteia of Hegemony, London \& New York, Verso, 2017.

Hannah Arendt, ¿Qué es la política?, Barcelona, Paidós. 1997

Antoine Artous, Marx, el Estado y la política, Barcelona, Editorial Sylone, 2016

CADEM), Encuesta de Opinión 20 de mayo 2018. Santiago: CADEM. 2018.

Juan Castañeda, Escándalos y Confianza Política en Chile, Avance Tesis Doctoral para el Grado de Doctor en Sociología. Santiago: Universidad Alberto Hurtado. 2018.

Manuel Castells, Comunicación y Poder. Madrid, Alianza, 2009.

CEP, Encuesta de Opinión Pública 2017, Santiago: CEP. 2017.

CIPER, Lo mejor de Ciper 3, Santiago, Editorial Catalonia, 2015.

COES, Encuesta Nacional de Opinión. Santiago, UDP, 2015.

Sergio Corzo, El Clientelismo Político, Granada, Universidad de Granada, 2002.

8 https://www.latercera.com/pulso/noticia/la-tutela-laboral-las-claves-del-fallo-impide-los-funcionarios-publicos-accedereste-procedimiento/443602/ visitado el 27/01/19

9 https://www.emol.com/noticias/Nacional/2018/12/08/930122/Carlos-Pena-y-aborto-El-caso-resuelto-por-el-TC-no-eraun-caso-de-autonomia-de-los-cuerpos-intermedios.html visitado el 27/01/19

10 https://www.elmostrador.cl/mercados/2019/01/25/otra-senal-del-tc-tribunal-falla-a-favor-de-motta-y-contesse-fica-yrebaja-multas-aplicadas-en-caso-cascadas/ visitado el 27/01/19 
John Durston, Nueva agenda de descentralización en Chile "Clientelismo político y actores populares en tres regiones de Chile", En Gonzalo Delamaza; Nuria Cunill y Alfredo Joignant, Santiago, Universidad de los Lagos-Ril. Pp. 369-391. 2012

Eduardo Engel, Informe de la Comisión Nacional de Ética Pública sobre la Probidad Pública y la Prevención de la Corrupción Santiago, Gobierno de Chile, 2015.

Robert Entman, Projections of power, Framing news, public opinion and US foreign policy, Chicago \& London, The University of Chicago Press. 2004.

Jeanifer Gandhir y Adam Przeworski, "Cooperation, cooptation and rebellion under dictatorships". En: Economics and politics, Vol. 18, pp.: 1-26. UK: Oxford, 2006.

Álvaro García Linera, Comunidad, Socialismo y Estado Plurinacional, Santiago, El Desconcierto, 2015.

Manuel Antonio Garretón, Neoliberalismo corregido, progresismo limitado, Santiago, Arcis. 2012.

Antonio Gramsci, Quaderni del Carcere. Edizione critica dell’Istituto Gramsci A cura di Valentino Gerratana, Torino, Einaudi editore, 2014.

Carlos Huneeus, La democracia semisoberana: Chile después de Pinochet, Santiago, Taurus. 2014.

Kerstin Jacobsson y Erik Löfmarck, A Sociology of Scandal and Moral Transgression, Acta Sociológica 2008.Vol 51(3): pp. 203-216, 2008.

Francisco Jiménez, Posibilidades del escándalo político como una forma de control social, Revista Española de Investigaciones Sociológicas (66). pp. 07-36, 1994.

Bernard Lander, Modelo de desarrollo en América Latina y sus contradicciones, Berlín, Heinrich Boll, 2014.

John Lull \& Sally Hinerman, En Búsqueda del Escándalo. Estudios Sobre las Culturas Contemporáneas, Vol

V. Universidad de Colima, pp. 61-93, 2000.

Alberto Mayol, El derrumbe del Modelo, Santiago, Lom. 2013.

Alberto Mayol, Frente Amplio en el momento cero, Santiago, Catalonia. 2017.

Ernest Mandel, El Poder y el Dinero, Mexico DF, Siglo XXI. 1994.

Daniel Matamala, Poderoso caballero el peso del dinero en la política chilena, Santiago, Catalonia, 2015.

Sighard Neckel, Political Scandals an Analytical Framework, Comparative Sociology, 4(1). pp. 101-114. 2005.

Edison Ortiz, http://www.elmostrador.cl/noticias/opinion/2018/02/27/el-legado-politico-cultural-de-laera-bachelet/ visitado el 29/8/2018.

Augusto Pavel, Odebrecht y la IIRSA norte y sur: un caso de corrupción y su influencia en las relaciones bilaterales con Perú en infraestructura durante los años 2005-2007, Tesis para optar por el grado de Magíster en Ciencia Política y Gobierno con mención en Relaciones Internacionales, Lima, PUCP, 2017.

Roberto Pizarro, http://www.eldesconcierto.cl/new/2018/10/10/la-responsabilidad-del-pt-en-el-triunfode-bolsonaro/. 2018, Revisado el 25 de enero 2019.

PNUD, Chile en 20 años: Un recorrido a través de los Informes sobre Desarrollo Humano, Santiago, PNUD, 2017.

Sergio Ramírez, Cuando todos hablamos, México, Alfaguara, 2008.

Pierre Rosanvallon, El buen gobierno, Buenos Aires, Ediciones Manantial, 2015.

Margarita Stolbyzer, La Corrupción K, Buenos Aires, Gen. 2016.

John Thompson, El escándalo político: poder y visibilidad en la era de los medios de comunicación, Barcelona, Editorial Paidós, 2001.

John Thompson, La transformación de la visibilidad, Estudios Públicos 90. pp 273-296, 2003.

León Trotsky, Los sindicatos y las tareas de los revolucionarios, Buenos Aires, Ediciones IPS-CEIP León Trotsky, 2010.

Arturo Valenzuela, Political brokers in Chile: Local government in a centralized polity, Durham, Duke University Press, 1977

Esteban Valenzuela y Pablo Yévenes Paolo, Aproximación al concepto de cooptación política: la maquinaria presicrática y sus formas, Polis 40. pp. 469-488. 2015.

Valenzuela, Esteban, Despoder y progresismo federalista fraterno para superar la izquierda presicrática, Polis 46. pp. 127-148. 2017. 